\title{
Learning curve for quantification of right ventricular size and systolic function in pulmonary arterial hypertension: comparison of cardiac magnetic resonance and three- dimensional echocardiography
}

\author{
Jonathan Afilalo ${ }^{1,2^{*}}$, Julia Grapsa ${ }^{3}$, Giuliana Durighel ${ }^{3}$, Declan ORegan ${ }^{3}$, David Dawson ${ }^{3}$, Robert A Levine ${ }^{2}$, \\ Petros Nihoyannopoulos ${ }^{3}$
}

From 15th Annual SCMR Scientific Sessions

Orlando, FL, USA. 2-5 February 2012

\section{Background}

Quantification of right ventricular (RV) volumes is challenging, particularly in patients with pulmonary arterial hypertension (PAH) who often have dilated and dysfunctional RVs. Several studies have shown that cardiac magnetic resonance (CMR) and 3-dimensional echocardiography (3DE) provide very reliable measurements of RV volumes when performed by experienced observers; however, little is known about the reliability and learning curve of these measurements when performed by novice observers. We sought to measure the inter- and intra-observer reliability of RV volume quantification by CMR and $3 \mathrm{DE}$ as it pertains to a novice observer with a progressive amount of experience over a 2 year period.

\section{Methods}

A prospective cohort of patients with idiopathic PAH was assembled at the Hammersmith Hospital (London, UK). Patients underwent CMR and 3DE at four time points: baseline, 6 months, 12 months, and 24 months. The scans were interpreted by a novice observer (level 1 training in echocardiography with no experience in CMR or $3 \mathrm{DE}$ ) on the day of the scan, by the same novice observer in the week following, and by an expert observer (level 3 training with $>5$ years experience in CMR and 3DE). For CMR, SSFP short-axis cine images

${ }^{1}$ Cardiac MRI, Beth Israel Deaconess Medical Center, Harvard University, Boston, MA, USA

Full list of author information is available at the end of the article were acquired using a $1.5 \mathrm{~T}$ system and endocardial contours were manually traced to obtain the RV end-diastolic volume, end-systolic volume, stroke volume, and ejection fraction. For 3DE, apical full-volume cine images were acquired and processed using a semi-automated algorithm (TomTec, Germany). Inter-observer reliability was calculated at the four time points with the use of the intraclass coefficient (ICC) and also the Bland-Altman limits of agreement; intra-observer variability was calculated with the ICC.

\section{Results}

Thirty patients were enrolled, representing $120 \mathrm{CMR}$ scans and 120 3DE scans. The mean baseline RV enddiastolic volume was $208+/-52 \mathrm{~mL}$, RV end-systolic volume was $141+/-50 \mathrm{~mL}$, and $\mathrm{RV}$ ejection fraction was $33+/-12 \%$ (by CMR). At the time point with least experience (30 scans interpreted), the novice observer had modest agreement with the expert observer for RV measurements as evidenced by relatively wide limits of agreement (Table). At the time point with most experience (120 scans interpreted), the novice observer improved and had good agreement with the expert observer for all measurements. Although the level of agreement was comparable between CMR and 3DE after 120 scans, it took 60 scans for the novice observer to reach this level with CMR while it took 120 scans with 3DE. With regard to the inter-observer reliability, the novice observer had good reliability with both CMR and 


\begin{tabular}{|c|c|c|c|c|}
\hline & \multicolumn{2}{|c|}{ CMR } & \multicolumn{2}{|c|}{ 3DE } \\
\hline & $\begin{array}{l}\text { Less experience } \\
\text { (30 scans) }\end{array}$ & $\begin{array}{c}\text { More experience } \\
\text { (120 scans) }\end{array}$ & \begin{tabular}{|c} 
Less experience \\
(30 scans)
\end{tabular} & $\begin{array}{c}\text { More experience } \\
\text { (120 scans) }\end{array}$ \\
\hline \multicolumn{5}{|l|}{ RV end-diastolic volume } \\
\hline Limits of agreement & -61 to $+23 \mathrm{~mL}$ & -24 to $+15 \mathrm{~mL}$ & -74 to $+53 \mathrm{~mL}$ & -23 to $+28 \mathrm{~mL}$ \\
\hline Inter-observer ICC & 0.88 & 0.98 & 0.80 & 0.97 \\
\hline Intra-observer ICC & 0.94 & 0.98 & 0.94 & 0.99 \\
\hline \multicolumn{5}{|l|}{ RV end-systolic volume } \\
\hline Limits of agreement & -50 to $+26 \mathrm{~mL}$ & -18 to $+11 \mathrm{~mL}$ & -62 to $+40 \mathrm{~mL}$ & -23 to $+28 \mathrm{~mL}$ \\
\hline Inter-observer ICC & 0.92 & 0.99 & 0.85 & 0.98 \\
\hline Intra-observer ICC & 0.97 & 0.99 & 0.94 & 0.99 \\
\hline \multicolumn{5}{|l|}{ RV stroke volume } \\
\hline Limits of agreement & -35 to $+21 \mathrm{~mL}$ & -19 to $+13 \mathrm{~mL}$ & -29 to $+30 \mathrm{~mL}$ & -17 to $+20 \mathrm{~mL}$ \\
\hline Inter-observer ICC & 0.81 & 0.90 & 0.69 & 0.88 \\
\hline Intra-observer ICC & 0.87 & 0.91 & 0.86 & 0.92 \\
\hline \multicolumn{5}{|l|}{$\underline{\text { RV ejection fraction }}$} \\
\hline Limits of agreement & -13 to $+15 \%$ & -6 to $+6 \%$ & -12 to $+18 \%$ & -7 to $+7 \%$ \\
\hline Inter-observer ICC & 0.85 & 0.93 & 0.70 & 0.88 \\
\hline Intra-observer ICC & 0.89 & 0.91 & 0.86 & 0.91 \\
\hline
\end{tabular}

Figure 1

$3 \mathrm{DE}$ after the first 30 scans, improving to very good reliability after 120 scans; it took 60 scans to see this improvement with CMR while it took 120 scans to see it with 3DE.

\section{Conclusions}

Novice observers can achieve high levels of inter- and intra-observer reliability for quantification of $\mathrm{RV}$ volumes after interpreting $60 \mathrm{CMR}$ scans and 120 3DE scans.

\section{Funding}

None.

\section{Author details}

${ }^{1}$ Cardiac MRI, Beth Israel Deaconess Medical Center, Harvard University,

Boston, MA, USA. Echocardiography, Massachusetts General Hospital,

Boston, MA, USA. ${ }^{3}$ Cardiology, Hammersmith Hospital, Imperial College NHS

Trust, London, UK.

Published: 1 February 2012
doi:10.1186/1532-429X-14-S1-P81

Cite this article as: Afilalo et al: Learning curve for quantification of right ventricular size and systolic function in pulmonary arterial hypertension: comparison of cardiac magnetic resonance and threedimensional echocardiography. Journal of Cardiovascular Magnetic Resonance 2012 14(Suppl 1):P81.
Submit your next manuscript to BioMed Central and take full advantage of:

- Convenient online submission

- Thorough peer review

- No space constraints or color figure charges

- Immediate publication on acceptance

- Inclusion in PubMed, CAS, Scopus and Google Scholar

- Research which is freely available for redistribution

Submit your manuscript at www.biomedcentral.com/submit
Biomed Central 